\title{
REDUKSI NILAI-NILAI NON-TAUHID DALAM KONTRUKSI WAYANG KARAKTER BATARA GURU
}

\author{
Ahmad Hidayatullah \\ Mahasiswa Pascasarjana Prodi KPI UIN Walisongo Semarang \\ Email: emboenimaji@gmail.com
}

\begin{abstract}
$J$

avanesse traditional shadow puppet (wayang) if we look through the story we can see that it is adapted from Hinduism. It was taken from great epic story. The ara Ramayana and Mahabharata. It does not wonder if we find opposite values beetwen Hinduism and monotheism (tauhid). It was noted by Walisongo at that time. They tried to do some reduction to things that opposite monotheism. They adapted inti Tauhid values so that they can di their mission successfully. In many adaption, we can take a look into the construction of Batara Guru's character. By using description analysis, this article to dig to know how deep Walisongo constructed Batara Guru's character to reduct values that opposite tauhid. As a result, the construction idea of Batara Guru -as a representation of Siva-does not hurt anybody. It is all caused by the wisdom and creativity of Walisongo in constructing the character of Batara Guru greatly and smartly.
\end{abstract}

Keyword: Javanesse traditional shadow puppet (wayang), Batara Guru, Walisongo, Islamic missionary.

\begin{abstract}
ABSTRAK
$\mathrm{K}$ esenian wayang dilihat dari segi cerita merupakan karya adoptif yang berasal dari ajaran Hindu, yakni dua epos besar Ramayana dan Mahabharata. Menjadi tidak mengherankan jika kemudian nilai Hinduisme yang bertentangan dengan nilai tauhid menjadi sesuatu yang begitu diperhatikan oleh Walisongo saat itu. Upaya reduksi terhadap nilai-nilai non-tauhid pada akhirnya dilakukan oleh Walisongo sebagai sebuah penyesuaian terhadap dakwah Islamiah yang mereka lakukan. Satu dari sekian banyak upaya itu terdapat dalam kontruksi penokohan Batara Guru. Menggunakan deskriptif analisis artikel ini mencoba menggali sejauh mana kontruksi terhadap karakter Batara Guru yang dilakukan dalam rangka mereduksi nilai-nilai non-tauhid. Alhasil kontruksi karakter yang sejatinya merupakan representasi dari Dewa Siwa ini dilakukan dengan tanpa melukai siapa pun pada saat itu. Semua itu karena kebijaksanaan dan kreatifitas Walisongo dalam mengkontruksi karakter Batara Guru secara apik dan cerdas.
\end{abstract}

Kata kunci: wayang, Batara Guru, dakwah, Walisongo 


\section{PENDAHULUAN}

Wayang merupakan seni pertunjukan yang sangat terkenal dalam berbagai bentuk di kawasan maritim dan daratan Asia Tenggara. Sementara di Indonesia, wayang hadir dalam beberapa bentuk, yakni wayang kulit, wayang golek dan wayang orang (Arps 2007, 55). Di Indonesia, Jawa khususnya, wayang yang dikenal sebagai sebuah masterpiece ( Sujarwo, dkk 2010) yang kali pertama diperhatikan secara serius pada era Prabu Jayabaya. Ia yang begitu gemar akan wayang, akhirya membuat gambargambar dan cerita-cerita wayang pada daun tal dalam tahun 939 Masehi. Wayang tersebut dinamakan wayang Rontal. Melihat ukurannya yang terlalu kecil untuk dipertunjukan, maka Raden Kudalaleyan -yang juga dikenal dengan Prabu Surya Hamiluhur- dari Pajajaran kemudian memperbesar ukuran gambar wayang tersebut di atas kertas pada tahun 1244 (Supriono, dkk 2008, 18).

Wayang sendiri dari segi cerita merupakan karya adoptif yang berasal dari ajaran Hindu, yakni Ramayana dan Mahabharata yang merupakan bagian dari kitab suci umat Hindu. Kitab suci umat Hindu terbagi dalam dua bagian, Pertama, Sruti, yakni kitab yang berisikan ajaran yang langsung diwahyukan Brahma (Zat Tunggal Maha Pencipta) kepada Rishi (orang suci), yaitu kitab suci Veda (Sou'yb 1996, 27). Kedua, Smriti, yakni setiap tradisi (ucapan, perbuatan, tulisan) yang mengandung ajaran seorang rishi (orang suci) atau ajaran seorang acharya (guru) atau pun ajaran avatar (ingkarnasiilahi) seumpama Krishna dan lainnya. Himpunan kitab yang termasuk dalam Smriti itu diantaranya termasuk
Brahmanas, Upanishads, Mahabharata, Bhagavadgita, Ramayana, Purana, dan Lainnya (Klostermaier 2003, 36).

Hanya saja fase awal kekuasaan Demak Bintoro ini kemudian juga menandai babak baru perkembangan wayang. Wayang sebagai sebuah media hiburan yang sudah begitu digemari masyarakat -baik anggota kerajaan maupun awam- pada era ini harus dihadapkan dengan kenyataan bahwa wayang dinilai Hinduistik, animistik, dan bahkan diharamkan karena tidak sesuai dengan ajaran Islam (Sudjarwo, dkk 2010, 51).

Walisongo yang dalam sumbersumber babad dianggap sebagai peletak pondasi terbentuknya pemerintahan Islam Kesultanan Bintoro Demak, tentu memberi perhatian khusus terhadap kesenian adoptif ini. Mereka menjadikan fakta tersebut sebagai tantangan sekaligus peluang dalam upaya untuk membumikan Islam di tanah Jawa agar masyarakat yang berada di bawah naungan Kesultanan baru ini tidak melenceng dari petunjuk $\mathrm{Al}$ Qur'an (Purwadi, dkk 2006, xvi). Akhirnya kontruksi karakter menjadi sebuah perhatian sebagai jawaban atas tantangan tersebut. Tujuannya tidak lain adalah untuk mereduksi nilai-nilai nontauhid untuk kemudian menyesuaikannya dengan nilai-nilai Islam yang sarat akan tauhid.

Satu di antara beberapa karakter pewayangan yang mengalami reduksi tersebut adalah Batara Guru atau yang dalam versi pra-Islam disebut diidentifikasikan sebagai Siwa. Siwa sendiri merupakan satu diantara tiga Dewa Trimurti (Wisnu dan Brahma) yang dalam ajaran Hindu merupakan manifest dari Sang Brahman (Tuhan). Maka menjadi 
menarik jika kemudian menjadikan Siwa sebagai objek kajian mengingat karakter ini menjadi titik salah satu titik tumpu bagi Walisongo untuk melakukan reduksi terhadap nilai-nilai non-tauhid.

\section{METODE PENELITIAN}

Penelitian ini menggunakan penelitian kualitatif. Menurut Gunawan (2013, 82), secara harfiah penelitian kualitatif adalah jenis penelitian yang temuan-temuannya tidak diperoleh melalui prosedur kuantifikasi, perhitungan statistik, atau bentuk cara-cara lainnya yang menggunakan ukuran angka. Penelitian kualitatif berarti sesuatu yang berkaitan dengan aspek kualitas, nilai atau makna yang terdapat dibalik fakta. Sementara menurut Bogdan dan Taylor sebagaimana dikutip Soewadji (2012, 5152) menyatakan bahwa penelitian kualitatif diartikan sebagai salah satu prosedur penelitian yang menghasilkan data deskriptif berupa ucapan atau tulisan dan perilaku orang-orang yang diamati.

Secara metodologis, penelitian ini termasuk dalam lingkup Library research (metode kepustakaan), yaitu penulisan dengan mengumpulkan data-data dari pustaka (Zed 2004, 3), utamanya yang berhubungan dengan karakter Batara Guru dalam cerita pewayangan. Selain itu literatur terkait dengan dakwah Walisongo juga tidak kalah penting menjadi rujukan dalam penelitian ini. Perpaduan antara berbagai literature tersebut diharapkan penelitian ini mampu mendapatkan hasil yang komprehensif.

Adapun analisis penelitian ini menggunakan analisis deskriptif, yaitu usaha untuk mengumpulkan dan menyusun suatu data, kemudian dilakukan analisis terhadap data tersebut
(Surakhmad, 1990: 139). Dalam menganalisis data, penulis menggunakan deskriptif analitik sebagai upaya untuk menguraikan dan menganalisis kontruksi yang dilakukan dalam pembangunan karakter Batara Guru. Hal ini bisa diidentifikasi melalui analisis terhadap karakter Batara Guru baik itu dikenal sebagai 'siwa' (versi pra Islam) maupun pasca digubah oleh Walisongo dalam bentuk dan karakter baru.

\section{PEMBAHASAN}

Bicara mengenai suatu karakter dalam wayang, maka harus melihat perkembangan serta transformasi dari karakter itu sendiri. Batara Guru sebagai sebuah 'karakter' dalam cerita wayang sejatinya sudah muncul dalam periode pra Islam sebagai salah satu Dewa Hindu, yakni Siwa. Maka dari itu guna mengetahui secara lebih mendalam perihal terjadinya 'transformasi makna' yang ada dalam kontruksi penokohan Batara Guru, peneliti akan mencoba menyajikan data terkait karakter ini dalam dua sudut pandang, yakni pra Islam -yang didominasi Hindu- serta pasca masuknya Islam.

\section{Batara Guru Versi Hindu (Siwa)}

Sebagaimana dijelaskan sebelumnya, bahwa Batara Guru tidak lain adalah gambaran peran wayang yang merupakan refleksi dari Dewa Siwa. Siwa sendiri merupakan dewa ketiga dari Trinitas agama Hindu adalah Dewa Perusak. Ia digambarkan sebagai seorang pertapa yang mengendarai lembu suci dan tempat tinggalnya di Kailasa. Ia mempunyai tangan empat,dan selalu berpakaian kulit macan dan berambut loreng dan seekor naga melingkar di lehernya. Lambang-nya 
adalah Lingga atau Phallus. Istrinya Parawati; Durga, dan dewi yang dahsyat Kali yang keduanya penjelmaan Parwati. Ganesha dewa keberuntungan yang berkepala gajah adalah yang paling terkenal dari antara anak-anak Siwa yang banyak itu (Samad 1990, 28). Dewa Siwa dalam berbagai kisah dilukiskan dalam berbagai inkarnasi: Ghandara, Mahadewa, Ishvara, Nilakanta, Nataraja. Bahkan Siwa dan istrinya Parvati belakangan dikembangkan dengan turunnya dua putra yaitu, Ganapati, penguasa bidang pertanian, dan Sabramanya/Skanda sebagai penguasa seluruh ular kobra (Sou'yb 1996, 51).

Sementara dalam kepercayaan Hindu Bali Siwa diyakini sebagai titik pusat dari delapan dewa penguasa mata angin, meliputi: Wishnu (Utara), Ishvara (Timur Laut), Shambu (Timur), Maheswara (Tenggara), Brahma (Selatan), Rudra (Barat Daya), Mahadewa (Barat), Changkara (Barat Laur). Pemeluk Hindu di Jawa dan Bali masa itu mengenalnya dengan Nawa Dewata (Sunyoto 2012, 112).

\section{Batara Guru Versi Wayang Purwa}

Pewayangan Jawa menggambarkan Batara Guru sebagai Siwa, hal ini ditandai dengan nama lain yang dimiliki Batara Guru salah satunya adalah Batara Syiwa (Sudibyoprono 1991, 337). Ia adalah dewa yang merajai kahyangan. Dia yang mengatur wahyu kepada para wayang, hadiah, dan ilmu-ilmu. Batara Guru mempunyai Istri Dewi Uma (Kapalaye 2010, 87). Pewayangan Jawa menyebutnya juga dengan nama "Sang Hyang Manikmaya" yang merupakan putra ketiga Sang Hyang Tunggal dengan Dewi Wirandi/Rekatawati, Putri Prabu
Yuyut/Resi Rekatama, Raja Samodralaya (Sudjarwo 2010, 114). Dia mempunyai dua saudara kandung, masing-masing bernama Sang Hyang Tejamaya/Batara Antaga (Togog) dan Sang Hyang Ismaya (Semar) (Aizid 2012, 80). Ia juga mempunyai tiga orang saudara seayah lain ibu putra Dewi Darmani, putri Sang Hyang Rudra/Dewa Esa, Sang Hyang Dewanjali, dan Sang Hyang Darmastuti (Sudjarwo 2012, 114).

Kelahiran Batara Guru dan dua saudara kandungnya ini diceritakan dalam Purwacerita sebagai berikut (Kaelola 2010, 318):

Dari perkawinan Sang Hyang Tunggal dengan Dewi Rekatawati, lahir sebutir telur yang bercahaya. Sang Hyang Tunggal dengan perasaan kesal membanting telur itu hingga pecah menjadi tiga bagian, yaitu cangkang, putih dan kuning telur. Ketiganya masingmasing menjelma menjadi laki-laki. Yang berasal dari cangkang diberi nama Antaga, yang berasal dari putih telur diberi nama Ismaya, sedangkan yang berasal dari kuning telur diberi nama Manikmaya. Pada suatu hari Antaga dan Ismaya berselisih karena masing-masing ingin menjadi pewaris tahta kahyangan. Keduanya pun mengadakan perlombaan menelan gunung. Antaga berusaha melahap gunung tersebut dengan sekali telan namun justru mengalami kecelakaan. Mulutnya robek dan matanya melebar. Ismaya menggunakan cara lain, yaitu dengan memakan gunung sedikit demi sedikit. Setelah melewati beberapa hari, seluruh bagian pun berpindah ke dalam tubuh Ismaya, namun tidak berhasil dikeluarkan. Akibatnya sejak saat itu Ismaya bertubuh bulat. Sang Hyang Tunggal murka mengetahui ambisi dan 
keserakahan kedua putranya itu. Mereka pun dihukum menjadi pengasuh Manikmaya, yang kemudian bergelar sebagai raja Kahyangan, bergelar Batara Guru. Antaga dan Ismaya pun turun ke dunia dan masing-masing memakai nama Togog dan Semar.

Cerita lain menyebut Batara Guru diberi kedudukan oleh ayahnya menjadi raja para dewa di kahyangan, sebab diantara kedua saudaranya ialah paling berwujud sempurna. Akan tetapi setelah mendapat kedudukan itu, ia justru menjadi sombong dan mengejek kedua kakaknya yang buruk rupa. Ini lantas membuat ayahnya menghukumnya hingga menjadi cacat (Aizid 2012, 80). Meski begitu, Batara Guru merupakan tokoh yang mempunyai kekuasan tertinggi, karena menguasai tiga buana: Mayapada (dunia kedewataan), Madyapada (dunia kehalusan/ alam jin syaitan) dan, Arcapada (dunia fana/ dunia manusia di bumi). Oleh karena itu, ia kemudian juga bergelar raja Tribuana (Sudibyoprono 1991, 332).

Adapun mengenai kisah Batara Guru dalam mendapatkan Dewi Uma dalam pewayangan diceritakan seperti berikut (Sudjarwo, dkk 2010, 114):

Sebelum mendapatkan Dewi Uma, semula Dewi Uma yang berparas cantik lagi sakti itu menolak untuk diperistri oleh Batara Guru, kecuali jika pemuka para dewa itu berhasil menangkapnya. Mereka pun berkejaran. Berkali-kali Batara Guru hampir mendapatkan wanita cantik itu, tetapi ia selalu saja dapat meloloskan diri. Tubuh Dewi Uma licin bagaikan belut, lagi pula gerakannya amat lincah dan gesit. Akhirnya Batara Guru memohon pada Sang Hyang Wenang, kakeknya, agar ia diberi sepasang tangan lagi yang diharapkan dapat membantu menangkap wanita cantik itu. Sesudah tangan Batara Guru menjadi empat, barulah Dewi Uma berhasil ditangkap, dan sesuai perjanjian ia harus menjadi istri Batara Guru. Karena bertangan empat itulah ia juga dikenal dengan Caturbuja.

Pernikahannya dengan Dewi Uma, menghasilkan banyak putra, diantarnya (sesuai urutan dari paling sulung menurut pewayangan Jawa) (Kapalaye 2010, 87):

- Batara Sambo

- Batara Brahma

- Batara Indra

- Batara Bayu

- Batara Wisnu

- Batara Ganesha

- Batara Kala

- Hanoman

Meski memiliki kedigdayaan serta kemuliaan posisi, namun dalam pewayangan, Batara Guru juga digambarkan dengan sisi negatif. Ia begitu mudah tergoda oleh nafsu (Aizid 2012, 83). Hal ini juga dibenarkan Sudjarwo dkk $(2010,117)$ yang menuturkan tentang sisi negatif dari karakter tokoh Batara Guru sebagaimana berikut:

Pada suatu senja hari, Batara Guru ingin bercumbu dengan Dewi Uma di punggung Lembu Andini, namun istrinya menolak. Pada peristiwa itu jatuhlah kama (sperma/mani) Batara Guru ke dasar samudra. Penolakan istrinya itu membuat Batara Guru marah. Ketika mereka telah kembali ke kahyangan, dan mereka pun bertengkar. Saat pertengkaran semakin memuncak, dengan kesal Dewi Uma berkata: "Kelakukan Kakanda hanya pantas dilakukan oleh mahluk bertaring..."

\section{Islamic Comunication Journal Volume 02, Nomor 01, Januari-Juni 2017


Karena Dewi Uma sebenarnya juga tinggi kesaktian, sumpahnya segera menjadi kenyataan. Saat itu juga taring gigi Batara Guru tumbuh memanjang. Batara Guru makin marah dan membalas mengutuk Dewi Uma sehingga istrinya itu berubah wujud menjadi raksasa. Setelah saling mengutuk keduanya merasa menyesal, namun 'nasi telah menjadi bubur'. Batara Guru kemudian memberi nama baru kepada Dewi Uma dengan Batari Durga.

Sementara itu, kama benih Batara Guru yang jatuh di dasar samudra menjelma menjadi mahluk ganas yang mengerikan. Mahluk itu membuat keonaran di dunia. Para dewa yang mencoba menghadapi mahluk ganas itu tidak berhasil mengatasinya. Mereka melarikan diri kembali ke kahyangan. Mahluk-mahluk itu pun menyusul para dewa yang melarikan diri itu, dan akhirnya berhadapan langsung dengan Batara Guru.

Kepada Batara Guru mahluk itu mengajukan tuntutan, minta diakui sebagai anak Batara Guru, minta nama dan diberi seorang istri. Batara Guru mengabulkan semua permintaan itu, ia diakui sebagai anak, diberi nama Batara Kala, dan Batari Durga ditunjuk sebagai istri untuk mendampingi mahluk itu. Tetapi yang menjadi istri Batara Kala hanyalah jasmani Batari Durga, sebab jiwanya telah berganti dengan jiwa Batari Permoni, seorang perempuan yang amat cantik, tetapi berhati dengki. Badan jasmani Batari Permoni yang cantik jelita dimasukan roh Dewi Uma. Dengan demikian, Batara Guru tetap beristri wanita cantik.

Batari Durga yang telah diganti jiwanya dengan jiwa Batari Permoni dan
Batara Kaa diperintahkan menghuni Setra Gandamayi (Gandamayit). Mereka diberi kekuasaan memerintah mahluk golongan jin, hantu, gandarwa, dan sejenisnya.

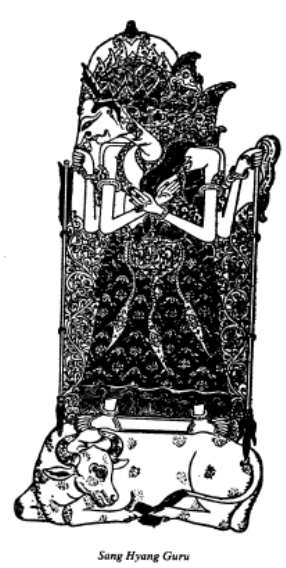

Gambar 1. Batara Siwa versi Wayang Jawa (Batara Guru),Sumber: Apa dan Siapa Semar

Dari penuturan di atas tentu tergambar jelas tentang sisi negatif dari karakter Batara Guru. Kadang ia juga diceritakan bertindak kurang bijaksana dalam mengatur kehidupan manusia (Aizid 2012, 83). Ia juga begitu mudah tergiur wanita cantik. Terhitung ia memiliki kepedak/ bidadari pengiring berjumlah tujuh, masing-masing bernama: Dewi Supraba, Dewi Wilutama, Dewi Lenglengdanu, Dewi Irimirim, Dewi Gagarmayang, Dewi Tunjungbiru dan Dewi Warsiki. Belum lagi ia juga mempunyai dayang-dayang berwujud Bidadari dan Hapsari (Sudibyoprono 1991, 336-337). Kekurangan lain dari sosok Batara Guru adalah ia mudah marah, mudah terbujuk dan mudah iri hati. Padahal ia memiliki kesaktian yang tinggi. Oleh karenanya dalam berbagai tindakannya yang salah, Batara Guru sering mendapat teguran dari Semar (Sudjarwo, dkk 2010, 94). Bahkan dalam 
Serat Kanda ia justru digambarkan sebagai sosok antagonis, sebab ia merupakan penyebar Sang Iblis, Ijajil dan mengaku 'Tuhan' (Mulyono 1989, 33).

Sementara dalam lakon Dewaruci, Batara Guru yang memiliki kedigdayaan sebagai penguasa Tribuana justru harus diruwat oleh Bima dalam wujud Sang Angkusprana. Adapun secara rinci, lakon Dewaruci terbagi dalam delapan tahapan (episode), sebagaimana berikut (Endraswara 2015, 171-173):

\section{Tahap pertama,}

Memuat kisah di gajah Oya. Duryudana sedang berdialog dengan Durna, tentang rencana pembunuhan terhadap Bima. Tiba-tiba BIma datang disambut dengan baik oleh keduanya. Ia diperintahkan untuk mencapai air suci mahapawitra dari sumur dorangga. Bima menjalankannya dengan sepenuh hati. Tanpa pikir panjang ia masuk ke sumur tersebut.

Atas perintah sang guru yang sangat dihormati, Bima ke sumur tersebut. Ia tidak menemukan air, melainkan sepasang ular naga membelitnya. Bima berhasil membunuhnya dengan kuku Pancanaka. Keduanya diruat menjadi bidadara dan bidadari yang tampan dan cantik bernama Sarambada dan Hamadi. Keduanya mengucapkan terimakasih kepada Bima. Bima kembali ke Hastinapura dan melaporkan kepada Drona. Ia dianjurkan ke hutan Amdadawa tempat keberadaan air suci.

\section{Tahap kedua,}

Berisi kisah bima menuju hutan Amdadawa. Bima tertipu lagi. Di hutan itu ia tidak menemukan air suci, melainkan berjumpa dengan raksasa Indrabahu yang ingin memangsanya. Terjadi perkelahian keduanya, dan raksasa berhasil dibunuh,

raksasa mati, tetapi muncul Dewa Indra menjumpainya dan mengucapkan terimakasih karena telah meruwatnya.

\section{Tahap ketiga,}

Bima mendapat punakawan ia mohon diri kepada ibu dan saudara-saudaranya. Karena ia dianjurkan ke dasar samudra tempat keberadaan air suci mahapawitra. Bima tenggelam ke dasar laut (akhirnya ia terdampar di sebuah pulau). Ia kagum melihat keindahan pulau tersebut. Berbagai macam tumbuhan dan binatang menghuni pulau tersebut. Sang Hyang Acintiya (nama lain Nawaruci) menciptakan berbagai macam makanan untuk menjamu Bima.

\section{Tahap keempat,}

Bima memndapat wejangan filosofis yang bertenden siwaistis, tentang arti hidup manusia. tujuannya, serta fungsi berbagai macam anggota badan dan hubungannya dengan kehidupan, tentang jenis kematian, sangkan-paran, dsb. Dalam memberikan wejang, Nawaruci minta agar Bima masuk ke dalam perutnya melalui telinga, setelah menerima wejangan secara tuntas, Bima mendapat nama baru, yaitu Awirota.

\section{Tahap kelima,}

Dengan nama Awirota, Bima meninggalkan Nusakambangan menuju Barunapada, tempat tinggal Sang Hyang Baruna, dan tertinggal dewa-dewa lain, seperti Brahmapada, Wisnupa Indrapada, dll. Selanjutnya ia menuju Amertajiwani di pertapaaan Siwamurti. Agar bisa masuk kesitu Bima harus mengalahkan penjaga pintu gerbang bernama Raja Panolah. Bima mendapatkan tirtakamandalu atau mahapawitra.

\section{Tahap keenam,}


Bima kembali ke Hastinapura untuk menyerahkan mahapawitra kepada Drona. Drona tidak percaya bahwa Bima berhasil mendapatkannya. Karena tujuan utama Drona bukan untuk mendapatkan air suci, melainkan ingin membunuhnya secara halus. Drona menghina Bima, Bima marah dan mendorongnya dalam laut, Bima tidak sampai hati melihat gurunya tenggelam lalu menolongnya.

\section{Tahap ketujuh,}

Bima meninggalkan Hastinapura menuju pertiwijati untuk bertapa, mengehningkan cipta dengan jalan menjauhi sesuatu yang bersifat duniawi dengan nama Angkuaprana. Bima mendapat restu dari para dewa, bahkan Sang Hyang Pramesthi Guru datang bersama Uma untuk merestuinya. Setelah memberikan berbagai macam godaan dan cobaan, Bima tetap tegar. Bima berdialog dengan paradewa tentang kebajikan dan kejahatan berdasar pada slokagama. Setelah itu Bima mendapat wejangan dari para dewa.

\section{Tahap kedelapan}

Bima berhasil mengalahkan godaan yang menimpanya. Ia juga meruwat Batara Guru dandewa-dewa lainnya. Para dewa menaruh hormat pada Angkusprana, lalu kembali ke kahyangan masingmasing. Bima kembali ke Indraprasta disambut oleh ibu dan saudarasaudaranya. Mereka mengadakan pesta pora untuk menyambut kedatangan Sang Angkusprana dengan kesaktian yang luar biasa.

\section{TEMUAN PENELITIAN}

Dewa Siwa terpapar di pembahasan sebalumnya telah digubah karakternya menjadi sosok Manikmaya yang kemudian juga dikenal dengan nama
Batara Guru. Penamaan Siwa menjadi Manikmaya dan Batara Guru tersebut tidak terlepas dari nilai-nilai Islam-Jawa yang ditanam oleh para Walisongo. Manikmaya berasal dari bahasa Arab; Ma + Nikma + Ya, yang berarti; Apa saja + Kenikmatan $+\mathrm{Ku}$. Manikmaya= Apa saja Kenikmatan-Ku (Allah). Penamaan tersebut ditujukan untuk menyadarkan manusia bahwa segala kenikmatan adalah mutlak berasal dari kebesaran Allah Swt (Padmosoekotjo 1979, 42). Pemilihan bahasa Arab dalam besutan nama baru Manikmaya adalah sebuah kewajaran sebab Islam sendiri berasal dari daratan Arab -utamanya ajaran inti Islam yang termaktub dalam Al-Qur'an juga berbahasa Arab-. Meski demikian Islamisasi di Jawa bukanlah proyek Arabisasi, sebab terbukti dialeg yang muncul masih menggunakan bunyi $(\mathrm{O})$ bukan (A) sebagai indentitas cara ucap/baca masyarakat Jawa. Setidaknya hal itu dimunculkan pada kultur oral masyarakat Jawa yang berada di Jawa Tengah-Jawa Timur sebagai area utama dakwah para Wali. Lain cerita ketika di area Jawa bagian Barat (utamanya Tanah Pasundan), menjadi sebuah keniscayan cara ucap/baca akan berbeda -cenderung menggunakan (A) daripada (O).

Sementara Batara Guru diambil dari Batara Paramesti Guru $=$ Parama + Esti + $\mathrm{Gu}+\mathrm{Ru}=$ Luhur + Tujuan + Gubahan + Baru = gubahan baru yang memiliki tujuan luhur (Padmosoekotjo 1979, 43). Makna yang dimunculkan tentu adanya sebuah upaya untuk merubah citra Hindu yang melekat erat pada Siwa, bergeser pada rasa baru Jawa-Islam. Urgensi dari penamaan tersebut adalah pola persuasif untuk menghilangkan ajaran Dewa yang sangat lekat dengan kesyirikan (dalam 
versi Islam) sebab jumlah Tuhan yang tidak lagi tunggal.

Ditinjau secara fisik, Siwa dalam mitologi Hindu digambarkan mempunyai tangan empat, dan selalu berpakaian kulit macan dan berambut loreng dan seekor naga melingkar di lehernya. Lambang-nya adalah Lingga atau Phallus. Melihat penggambaran karakter tersebut, sebenarnya tidak jauh berbeda dengan yang digubah dalam dunia pewayangan Jawa. Siwa dalam gubahan baru berwujud Manikmaya/Batara Guru juga digambarkan hampir sama, utamanya pada sisi ikonik tangan empat (Catur Boja yang melekat pada karakter ini). Namun perbedaan yang terdapat pada keduanya bisa dilihat dari latar belakang perihal wujud karakter yang didapat.

Semisal tentang bagaimana Manikmaya/Batara Guru memiliki tangan empat. Sisi kekosongan alur penceritaan yang terdapat dalam Hindu, sebab Siwa bertangan empat tidak memiliki latar belakang perihal bagaimana sampai karakter berjuluk Dewa Perusak ini berCatur Boja, membuat para Wali memainkan perannya. Kemudian lahir sebuah alur di mana Batara Guru ingin mendapatkan Dewi Uma, yang pada akhirnya memohon Sang Kakek, Sang Hyang Wenang untuk menambahkan sepasang tangan lagi agar bisa menangkap Dewi pujaannya yang sedemikian gesitnya, sebagai sebuah syarat yang memang harus dipenuhi jika ingin mempersuntingnya.

Melihat penggubahan alur cerita di atas, tentu jika diamati secara lebih mendalam terdapat proses desakralisasi dalam upaya mereduksi mitos-mitos yang sebelumnya tertanam dalam masyarakat Jawa pemeluk Hindu. Tangan empat yang diperolehnya seolah-olah menampakkan sebuah pesan tentang ketidak mampuan Sang Dewa, bahkan hanya untuk menangkap seorang Dewi (yang tentu derajatnya tidak lebih tinggi darinya). Dewa yang sarat akan ke-Maha Kuasa-an pada akhirrnya tereduksi dengan sendirinya saat sisi manusiawi dilekatkan oleh Walisongo pada karakter Batara Guru.

Proses reduksi ini semakin bertambah lagi saat tokoh baru Sang Hyang Wenang diposisikan sebagai sebuah solusi atas munculnya intrik konflik yang dimunculkan dalam gubahan alur baru. Siwa yang dalam Hindu merupakan satu dari tiga simbol tertinggi agama budaya ini (disebut juga Trimurti), dipaksa harus tunduk memohon peran tokoh Dewa lain guna memenuhi keinginannya untuk meminang Dewi Uma. Secara lugas tentu tidak berlebihan jika makna yang sedang dibangun adalah Batara Guru sudah pasti tidak sehebat leluhurnya Sang Hyang Wenang yang mampu memberinya sepasang tangan lagi.

Selain itu secara silsilah (nasab) dalam pewayangan, meletakkan Sang Hyang Wenang sebagai keturunan Nabi pada garis keturunan Nabi Adam, yakni melalui jalur Nabi Sis. Berikut adalah silsilah pewayangan tersebut (Soedjarwo, ddkk 2010, 218-219): 


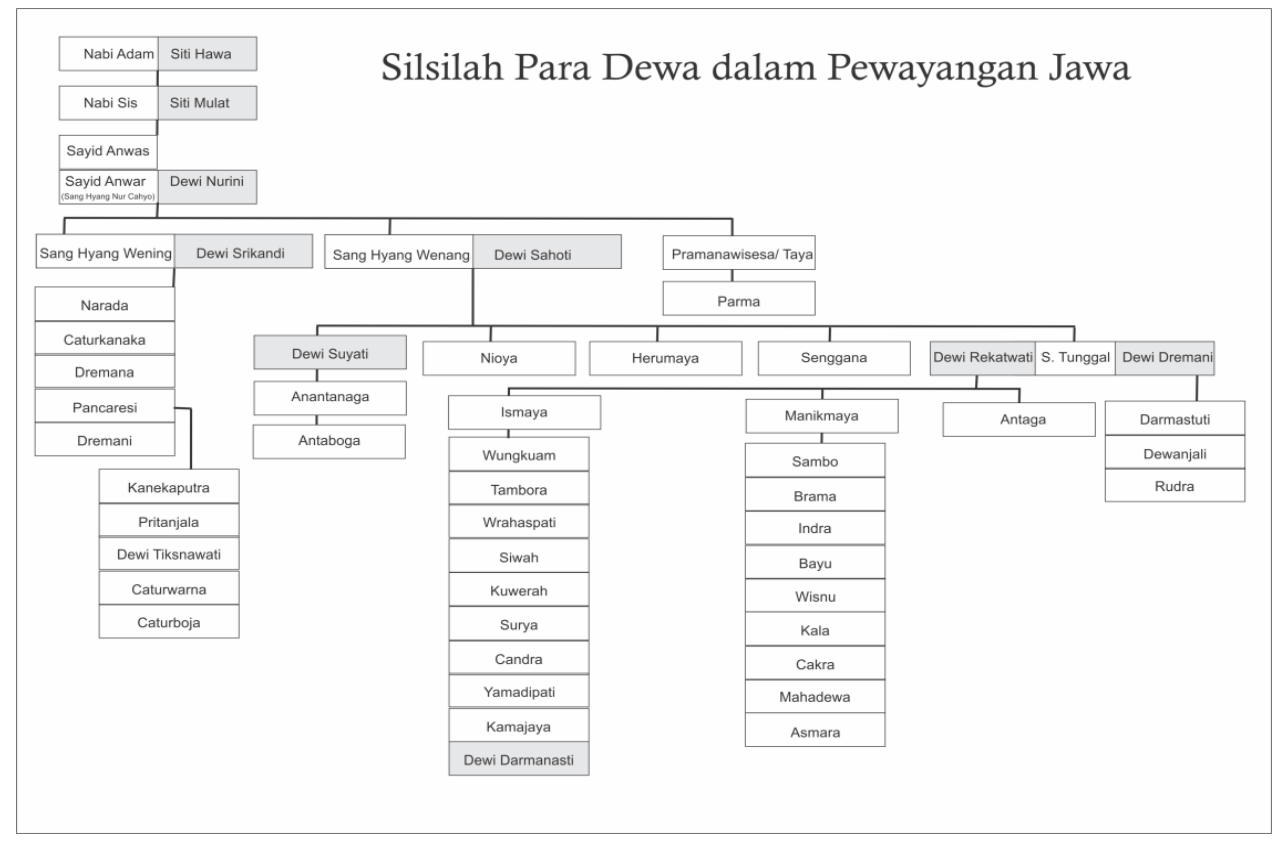

Peletakkan Siwa sebagai keturunan Sang Hyang Wenang dan kemudian berada di bawah silsilah Nabi Adam sejatinya merupakan proses yang dikontruksi oleh Walisongo sedang ingin melakukan tindakan memanusiakan 'Siwa' yang notabene merupakan Dewa yang disembah oleh masyarakat Jawa saat itu. Artinya jika dalam ajaran Hindu, Brahman sebagai Tuhan alam semesta, bukan meletakkan Siwa sebagai sebuah tatanan hirarki (atas-bawah) tetapi lebih

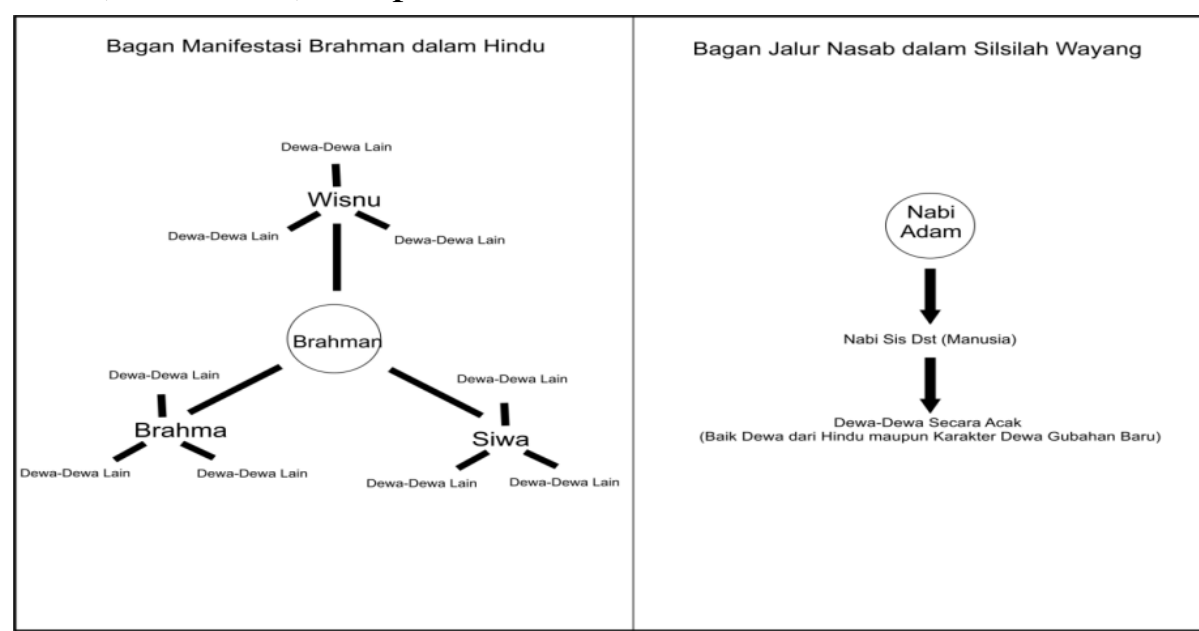

Gambar. 2. Ilustrasi Bagan Perbandingan antara manifestasi dan jalur nasab kepada manifestasi dari wujudnya (sejajar), maka dalam wayang Dewa diletakkan pada posisi atas-bawah, tinggirendah, dahulu-belakangan, lama-baru, di bawah manusia pertama bernama Adam. Dengan kata lain Siwa dalam wujudnya yang baru (Batara Guru) sedang mengalami reduksi karena otomatis mahluk yang lahir dari manusia, tentu dia adalah manusia juga apa pun itu namanya. Berikut ilustrasinya:

\section{para Dewa versi ajaran Hindu dan Wayang Jawa}


Aspek lain yang muncul sebagai sebuah upaya reduksi nilai non-tauhid adalah kisah lahirnya mahluk raksasa jahat Batara Kala -dari Rahim Dewi Umaakibat dari karakter Batara Guru yang saat itu haus seksual, dan berbuntut pada pengutukan istrinya sendiri menjadi raksasa perempuan yang buruk rupa bernama Batari Durga. Karakter Don Juan kian dipertegas lagi dengan munculnya tokoh-tokoh baru berwujud bidadari berjumlah tujuh sebagai selirnya, masingmasing bernama: Dewi Supraba, Dewi Wilutama, Dewi Lenglengdanu, Dewi Irimirim, Dewi Gagarmayang, Dewi Tunjungbiru dan Dewi Warsiki. Belum lagi ia juga mempunyai dayang-dayang berwujud Bidadari dan Hapsari
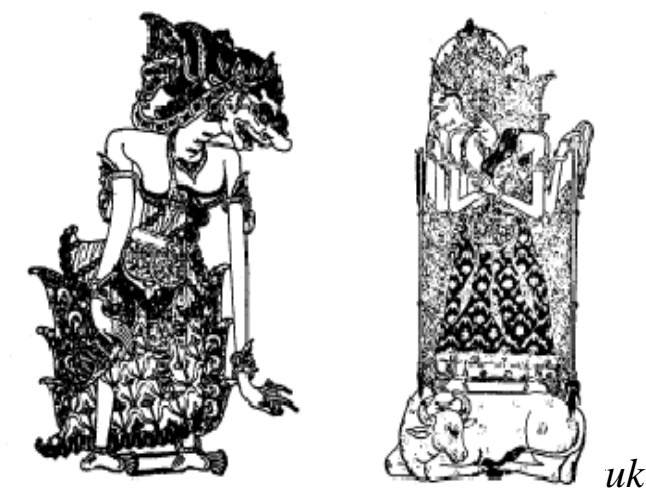

menjadi Batari Durga oleh Batara Guru. Sumber: Pedhalangan Jilid I.

Sebagai seorang Dewa yang idealnya suci dari sisi buruk kemanusiawian, dalam wayang hal itu justru menjadi sebuah keniscayaan. Ke-Maha Benar-an seorang Batara Guru sebagai salah satu wujud yang dipuja/disembah pada akhirnya dipertanyakan. Menjadi tidak mengherankan kemudian jika tokoh baru yang lain dimunculkan sebagai antitesis ke-Maha Benar-an Manikmaya, yakni Ismaya yang kemudian menitis menjadi
Semar. Saudara kandung yang menjadi abdi Pandawa di kemudian hari inilah yang dalam alur pewayangan baru dihadirkan sebagai 'warning' atas berbagai kekeliruan dan kekhilafannya.

Selain itu reduksi nilai non-tauhid juga terjadi pada saat Batara Guru dihadirkan dalam lakon Dewaruci. Bima dalam adegan di atas digambarkan meruwat para Dewa, utamanya Dewa yang memiliki kasta tinggi dalam pewayangan -apalagi Hindu- yakni Batara Guru (Siwa). Perlu diketahui bahwa ruwat dalam dalam kamus Bahasa Jawa Kuna memiliki arti dibuat tidak berdaya, hancur, binasa (kejahatan, kutuk, pengaruh jahat), Sedangkan anruwat, rumuwat, rinuwat, yakni menyebabkan tidak berdaya, menghancurkan; membebaskan (dari kejahatan dll), membebaskan dari roh jahat (Zoetmulder dan Robson 2011, 967).

Setidaknya kata meruwat memiliki makna mendekati dengan kata anruwat, yakni membebaskan dari hal-hal yang buruk yang membuat tidak berdaya seseorang. Jika dibenturkan pada konteks kebahasaan, logikanya orang yang melakukan ruwat harus memiliki kemampuan lebih atas objek (orang) yang diruwat. Jika logika tersebut diterapkan, maka lagi-lagi tidak salah jika mengatakan ini sebagai proses reduksi terhadap Batara Guru (Siwa) sebab ia digambarkan -setidaknya dalam kasus iniberada satu trap di bawah Bima yang hanya seorang manusia.

\section{PENUTUP}

Kontruksi karakter Batara Guru yang sejatinya merupakan representasi dari Dewa Siwa dilakukan dengan kebijaksanaan dan kreatifitas Walisongo secara cerdas dan tanpa melukai siapapun.

Islamic Comunication Journal Volume 02, Nomor 01, Januari-Juni 2017 
Meskipun Siwa merupakan salah satu simpul ajaran Hindu yang notabene merupakan ajaran non-tauhid tidak serta merta membuat Walisongo membabi-buta dalam memberangus ajaran dan keyakinan yang dimiliki oleh masyarakat Jawa saat itu. Akhirnya menginternalisasikan nilai- nilai tauhid secara persuasif dan infiltratif melalui kesnian menjadi stategi jitu berbasis kultural yang terbukti memunculkan hasil luar biasa. Adapun proses reduksi nilai-nilai non tauhid dalam kontruksi karakter Batara Guru secara garis besar terdapat dalam tabel berikut:

\begin{tabular}{|c|c|c|}
\hline $\begin{array}{c}\text { Siwa Versi Ajaran } \\
\text { Hindu }\end{array}$ & $\begin{array}{c}\text { Siwa Versi } \\
\text { Pewayangan (Batara } \\
\text { Guru) }\end{array}$ & $\begin{array}{lr}\text { Proses Reduksi Nilai-Nilai } \\
\text { Non-Tauhid } & \text { dalam } \\
\text { Kontruksi Karakter } & \text { Batara } \\
\text { Guru } & \end{array}$ \\
\hline $\begin{array}{l}\text { Manifestasi } \\
\text { Brahman, salah } \\
\text { satu dari Trimurti. }\end{array}$ & $\begin{array}{l}\text { Bernama Sang Hyang } \\
\text { Manikmaya (Batara } \\
\text { Guru) putra Sang } \\
\text { Hyang Tunggal. }\end{array}$ & 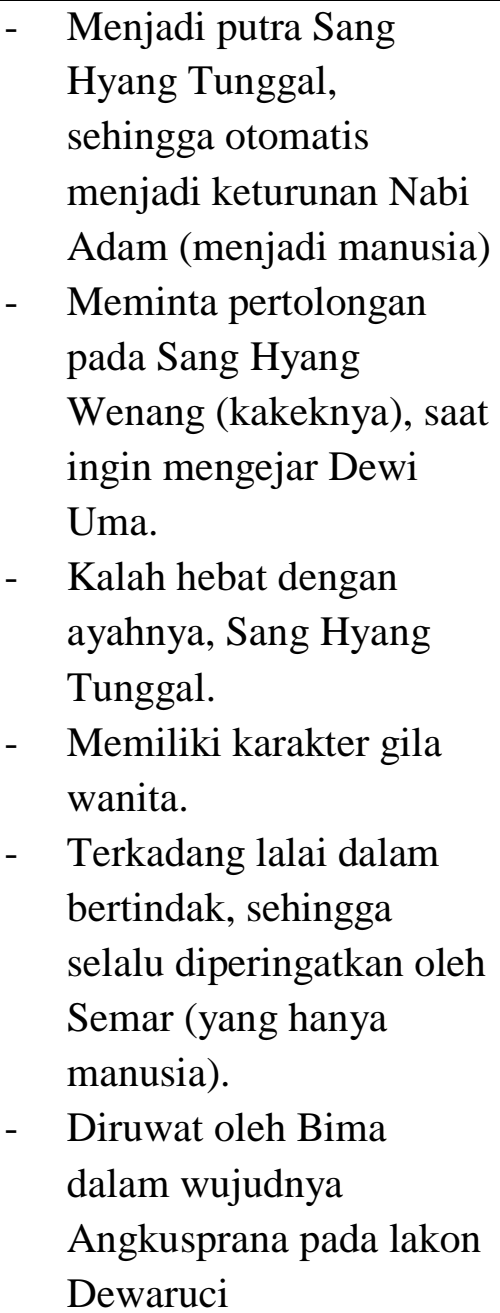 \\
\hline
\end{tabular}




\section{DAFTAR PUSTAKA}

Aizid, Rizem, 2012. Atlas Tokoh-Tokoh Wayang, Yogyakarta: Diva Press.

Arps, Bernard. 2007. Writings on Wayang: Approrches to Puppet Theatre in Java And Bali in Fifteen Recent Books Indonesia Circle. London : School of Oriental \& African Studies. Newsletter.

Gunawan, Imam. 2013. Metode Penelitian

Kualitatif: Teori dan Praktik. Jakarta: Bumi Aksara.

Kaelola, Akbar, 2010. Mengenal Tokoh Wayang Mahabharata, Yogyakarta: Penerbit Cakrawala.

Kapalaye, Ki Ageng, 2010. Kamus Pintar Wayang (Dari Versi India Hingga Pewayangan Jawa), Yogyakarta: Laksana.

Kasdi, Aminuddin, 2005. Memahami Sejarah. Surabaya : Unesa Press.

Klostermaier, Klaus K., 2003. A Concise Encyclopedia of Hinduism. Oxford: Oneworld Publication.

Mulyono, Sri, 1989. Apa dan Siapa Semar. Jakarta: CV. Haji Mas Agung.

Padmosoekotjo, S., 1979. Silsilah Wayang Purwa Mawa Carita Jilid. Surabaya: CV. Citra Jaya.

Purwadi, dkk, 2006. Jejak Para Wali dan Ziarah Spiritual, Jakarta: Kompas.

Samad, Uflat Aziz-us, 1990. AgamaAgama Besar di Dunia terj. Great Religions of the World, Bombay: Mr. Abdur Razaak. Ebookww.aaiil.com.
Soewadji, Jusuf. 2012. Pengantar Metodologi Penelitian. Jakarta: Penerbit Mitra Wacana Media.

Sou'yb, Joesoef, 1996. Agama-Agama Besar di Dunia. Jakarta: PT. Al Husna Zikra.

Sudibyoprono, R. Rio, 1991. Ensiklopedi Wayang Purwa, Jakarta: Balai Pustaka.

Sudjarwo, Heru S., dkk, 2010. Rupa dan Karakter Wayang Purwa, Jakarta: Kaki Langit Kencana Prenada Media Group.

Sunyoto, Agus, 2012. Atlas Walisongo. Depok: Pustaka IIMaN.

Supriono, dkk, 2008. Pedhalangan Jilid 1. Jakarta: Departemen Pendidikan Nasional.

Surakhmad, Winarno, 1990. Pengantar Penelitian Ilmiah: Dasar,Metode, dan Teknik. Bandung: Tarsito.

Zed, Mestika, 2004. Metode Penelitian Kepustakaan. Jakarta: Yayasan Obor Indonesia.

Zoetmulder, P.J. dan Robson, S.O., 2011. Kamus Jawa Kuna - Indonesia. Jakarta: Gramedia Pustaka Utama.

Pada 7 November 2003, UNESCO menetapkan seni wayang sebagai Masterpiece of the Oral and Intageble Heritage of Humanity, karena wayang dianggap bernilai tinggi bagi peradaban manusia. Baca: Sujarwo, dkk (2010), xxxiv. 